\title{
Performance investigation of stand-alone induction generator based on STATCOM for wind power application
}

\author{
Ahmed J. Ali, Mohammed Y. Suliman, Laith A. Khalaf, Nashwan S. Sultan \\ Northern Technical University, Technical Engineering College, Iraq
}

\begin{tabular}{l}
\hline \hline Article Info \\
\hline Article history: \\
Received Jul 8, 2019 \\
Revised Apr 7, 2020 \\
Accepted May 1, 2020 \\
\hline
\end{tabular}

\section{Keywords:}

Dynamic operation

Excitation capacitance

Neuro-fuzzy

Self-excited induction generators STATCOM

\begin{abstract}
Self-Excited induction generators (SEIG) display a low voltage and frequency regulation due to variable applied load and input rotation speed. Current work presents a simulation and performance analysis of a three-phase wind-driven, SEIG connect to a three-phase load. In addition, an investigation of the dynamic operation of the induction generator from starting steady state until no-load operation. It is assumed that the input mechanical power is constant where the rotor of the SEIG rotates at a constant speed. The value of the excitation capacitance which is necessary to the operation of the induction generator also computed to ensure a smooth and self-excitation starting. The output voltage of the generator is adjusted by varying the reactive power injected by STATCOM. A 3-phase IGBT voltage source inverter with a fuel cell input supply is connected as STATCOM which is used to compensate for the reduction in the supply voltage and its frequency due to variation occurred in the applied loads. This work includes introducing a neuro-fuzzyy logic controller to enhance the performance of the SEIG by regulation the generated voltage and frequency. The dynamic model of SEIG with STATCOM and loads are implemented using MATLAB/SIMULINK.
\end{abstract}

Copyright (c) 2020 Institute of Advanced Engineering and Science. All rights reserved.

Corresponding Author:

Ahmed J. Ali,

Technical Engineering College,

Northern Technical University,

Mosul, Iraq

Email: ahmed.j.ali@ntu.edu.iq

\section{INTRODUCTION}

Due to a severe increase in the electric demand especially in rulers, agricultural fields and remote areas, an off-grid electric system has been extensive dispersion of power generation to use the stand-alone generation systems that reduce both stress and coasts on national electric grid and consumers. In addition, these types of energy sources consider an important factor used to reduce the effect of pollution produced from conventional generation units. A 3-phase cage rotor induction machine can be operated in a generation mode when it is supplied by a reactive power on the stator terminals. Three-phase bank capacitances in star or delta form will be connected across the terminals of the generator in order to supply the initial field current required. The electrical machine with this connection normally called a SEIG [1]. These types of generators have wide acceptance in stand-alone regions due to low coast, rigidity, reliability and low maintenance requirements. However, it has some drawbacks like poor voltage regulation, in addition, the frequency of the generated voltage is variable and depending on the applied loads $[2,3]$. Therefore, the generated voltage of the SEIG should be regulated during load variations. Numerous voltages regulating arrangements have been used to improve the regulation of SEIG. These methods depend on insert capacitance elements in parallel, series or both together on the terminal of a generation system for voltage regulation. The voltage SEIG can be compensated using short shunt or long shunt capacitance to supply the required reactive power where this method includes inserting an only passive element in the system. The drawback of the methods is 
the inability to regulate the frequency and voltage during severe changes of load [4-6]. Static var compensation is another method used to regulate the terminal voltage of SEIG. It is consisting of a fixed capacitor with power electronic switches-controlled inductor, but low order harmonic current components generated due to switching in addition to big weight and size [7, 8]. Static synchronous compensator (STATCOM) is another method had been used with SEIG by providing a continuous adjustable reactive power to maintain a constant terminal voltage. This type of compensation exhibits a better dynamic behavior, which enhances the voltage regulation of the system $[9,10]$. Several researchers in recent years have presented many techniques aimed at SEIG. These techniques include the use of SVC with a fuzzy controller [11]. The bank of capacitors and a variable inductor with a fuzzy controller [12], the Electrochemical Battery is used as an energy storage system (ESS) [13]. In this paper, a balanced and unbalanced three-phase R-L load have supplied by a 3- $\Phi$ SEIG in which deformation and reduction of the generated voltages and currents in addition to side-band harmonics are injected in the system. To compensate these effects a STATCOM has been connected to the induction generator to produce the required reactive power and removes the effects of harmonics. In case of an increase or decrease in the applied load the motor speed of SEIG will accelerate or decelerate which leads to change the value of voltage and it is frequency. A neural network with a fuzzy system based static synchronous compensator with two inputs and one output has been effectively used to regulate the SEIG generated.

A self-exited induction generar (SEIG) in D-Q model with an excitation capacitance on the stator terminals of the generator. The general form of voltage equations sets that can be used to explain the dynamic model of the SEIG will be stated as follows [14]:

The voltage equations of the stator region are given by:

$$
\begin{aligned}
& v_{D s}=R_{s} i_{D s}+k \lambda_{D s} \\
& v_{Q s}=R_{s} i_{Q s}+k \lambda_{Q s}
\end{aligned}
$$

where $v_{D s}$ and $v_{Q s}$ are the $\mathrm{D}$ and $\mathrm{Q}$ stator voltages, $\mathrm{R}_{\mathrm{s}}$ is the resistance of the stator winding, $\mathrm{i}_{\mathrm{Ds}}$ and $\mathrm{i}_{\mathrm{Qs}}$ are the $\mathrm{D}$ and $\mathrm{Q}$ stator currents, $\mathrm{k}$ is a differential operator, $\lambda_{\mathrm{Ds}}$ and $\lambda_{\mathrm{Qs}}$ are the linkage magnetic flux of the stator in D-Q axes.

The voltage equations of the rotor region are given by:

$$
\begin{aligned}
& v_{D r}=R_{r} i_{D r}+k \lambda_{D r}+w_{r} \lambda_{Q r} \\
& v_{Q r}=R_{r} i_{Q r}+k \lambda_{Q r}-w_{r} \lambda_{D r}
\end{aligned}
$$

where $v_{D r}$ and $v_{Q r}$ are the $\mathrm{D}$ and $\mathrm{Q}$ rotor voltages, $\mathrm{R}_{\mathrm{r}}$ is the resistance of the rotor bars, $\mathrm{i}_{\mathrm{Dr}}$ and $\mathrm{i}_{\mathrm{Qr}}$ are the $\mathrm{D}$ and $\mathrm{Q}$ stator currents, $\mathrm{k}$ is a differential operator, $\lambda_{\mathrm{Dr}}$ and $\lambda_{\mathrm{Qr}}$ are the linkage magnetic flux of the rotor in D-Q axes, $\mathrm{w}_{\mathrm{r}}$ is the relative speed of the rotor [15]. The expression for electromagnetic torque in terms of the stationary reference variables can be expressed as:

$$
T_{d}=1.5 \frac{p}{2}\left(\lambda_{D S} \cdot i_{Q s}-\lambda_{Q s} \cdot i_{D S}\right)
$$

The rotor speed is defined by:

$$
\frac{d}{d t} \theta_{r}=\frac{1}{J} \frac{p}{2}\left(T_{e m}-T_{L}\right)
$$

where, $\theta_{\mathrm{r}}$ is the angular position of the rotor, $\mathbf{J}$ is the effective inertia of the wind turbine and the induction generator. $T_{\mathrm{L}}$ is the output torque of the wind turbine. The generated voltage of the SEIG can be obtained by the following formulas $[14,1]$ :

$$
\begin{aligned}
& V_{a}=-\frac{1}{C_{a}} \int i_{c a} \\
& V_{b}=-\frac{1}{C_{b}} \int i_{c b}
\end{aligned}
$$




$$
V_{c}=-\frac{1}{C_{c}} \int i_{c c}
$$

\section{STATCOM MODEL AND CONTROL}

The STATCOM injects almost sinusoidal voltage with variable amplitude. Voltage source inverter (VSI) is the heart of STATCOM is with a D.C input voltage [16]. The fundamental configuration of STATCOM with SEIG shown in Figure 1. Without energy in the DC side, the STATCOM output has two components: quadrature component with the current of the line that emulates capacitive or inductive effect in parallel for compensated line, the second component is in-phase with respect to the current of line, this for cover the losses in the inverter. If the compensated voltage leads current in the line "capacitive reactance emulated", in parallel with transmission system, and this will increase the flow of power, and when "inductive reactance emulated" the, causing the current and flow of power through the line to decrease [17].

The controller can adjust rapidly both the magnitude and phase of injected compensating voltage. The transmitted active power $(\mathrm{P})$ and load voltage $(\mathrm{V})$ become a parametric function of the compensated voltage. Therefore, the transmittable power can increase or decrease by reversing the injected voltage "the polarity". If the compensated voltage is made larger than the difference between sending and receiving end systems $(\mid$ Vcomp $|>| V s-V r \mid)$ this will reverse the power flow. STATCOM has a response time of (sub-cycle) and also the transition from positive power flow to reverse in the line is continuous and smooth [18]. A typical powers flow control using STATCOM is shown in Figure 2.

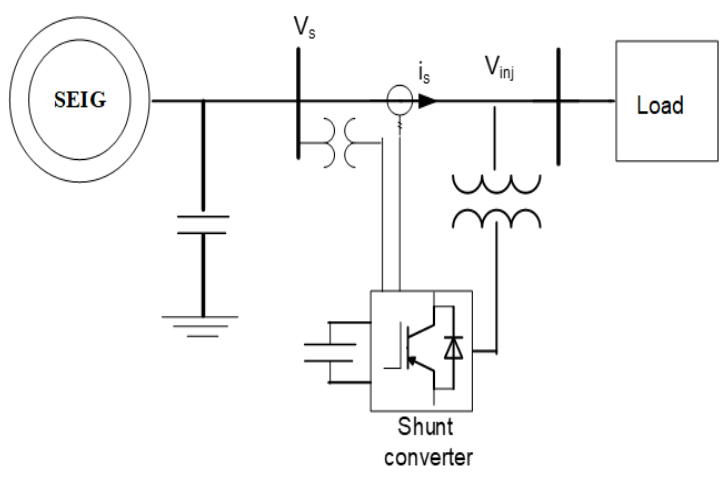

Figure 1. Fundamental configuration of STATCOM with SEIG
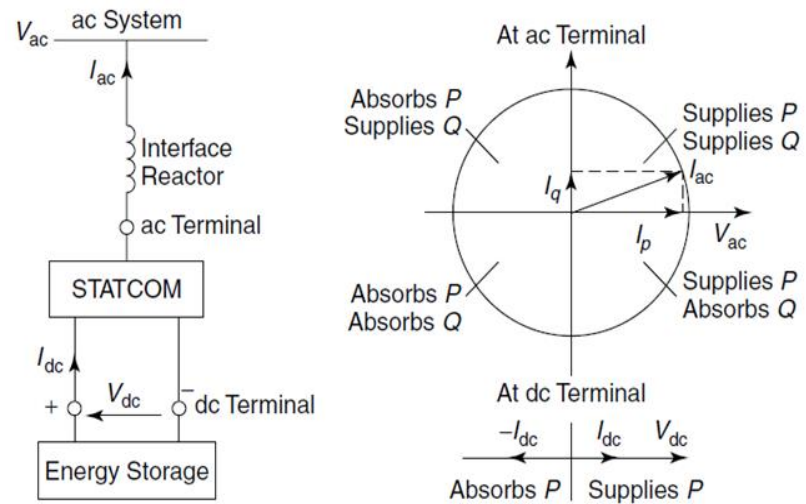

Figure 2. The power exchange between STATCOM and the ac system

\section{MEASURING LOAD VOLTAGE AND ACTIVE POWER}

In order to measure the load voltage and active power, the DQ theory is used in this paper. D-q theory is valid for operating in transient and steady-state, based on time-domain, and also can be used in different waveforms of voltage and current in the power system. The main advantage of this theory is the simplicity calculations, that involve "algebraic calculation" and the ability to separate the alternated and mean values of the power components [19]. The DQ-theory represented by a "park transformation" of a "stationary coordinates" of the reference system to "rotating coordinates" [20]. The theory applied for the time frame "i.e. $\mathrm{va}, \mathrm{vb}$ and $\mathrm{vc} "$ is as follows:

$$
\left[\begin{array}{l}
v_{d} \\
v_{q} \\
v_{0}
\end{array}\right]=\frac{2}{3}\left[\begin{array}{ccc}
\cos (\varnothing) & \cos \left(\varnothing-\frac{2 \pi}{3}\right) & \cos \left(\varnothing+\frac{2 \pi}{3}\right) \\
-\sin (\varnothing) & -\sin \left(\varnothing-\frac{2 \pi}{3}\right) & -\sin \left(\varnothing+\frac{2 \pi}{3}\right) \\
\frac{1}{2} & \frac{1}{2} & \frac{1}{2}
\end{array}\right]\left[\begin{array}{l}
v_{a} \\
v_{b} \\
v_{c}
\end{array}\right]
$$




$$
\begin{aligned}
& {\left[\begin{array}{l}
i_{d} \\
i_{q} \\
i_{0}
\end{array}\right]=\frac{2}{3}\left[\begin{array}{ccc}
\cos (\varnothing) & \cos \left(\varnothing-\frac{2 \pi}{3}\right) & \cos \left(\varnothing+\frac{2 \pi}{3}\right) \\
-\sin (\varnothing) & -\sin \left(\varnothing-\frac{2 \pi}{3}\right) & -\sin \left(\varnothing+\frac{2 \pi}{3}\right) \\
\frac{1}{2} & \frac{1}{2} & \frac{1}{2}
\end{array}\right]\left[\begin{array}{c}
i_{a} \\
i_{b} \\
i_{c}
\end{array}\right]} \\
& \varnothing=(\omega t+\theta)
\end{aligned}
$$

where $\phi$ is the phase shift between the fixed and rotating coordinate and $\theta$ represents the angle of the voltage. From (1) and (2), the power and load voltage compensated find by:

$$
\begin{aligned}
& p=V_{d} I_{d}+V_{q} I_{q} \\
& V=\sqrt{V_{d}^{2}+V_{q}^{2}}
\end{aligned}
$$

\section{STATCOM CONTROL SCHEME}

The control system is shown in Figure 3. The active power and load voltage are calculated depending on the line voltages and currents and. The P and V vectors as a feedback input to the closed loop system. The reference Pref and Vref are compared with the P and V respectively for generating output signals $\left(\right.$ Erorr $\left._{\mathrm{p}}\right)$ and $\left(\right.$ Erorr $\left._{\mathrm{v}}\right)$ as:

$$
\begin{aligned}
& \operatorname{Erorr}_{P}=P_{\text {ref }}-P \\
& \operatorname{Erorr}_{V}=V_{\text {ref }}-V
\end{aligned}
$$

The phase angle of the injected voltage can be adjusted to make the compensation either in capacitive mode or inductive mode by change the sign of the signal.

$$
\delta=\emptyset \pm \gamma
$$

Where $\gamma$ can be adjusted in capacitive/inductive mode operations depending on the sign of the Error in (8).

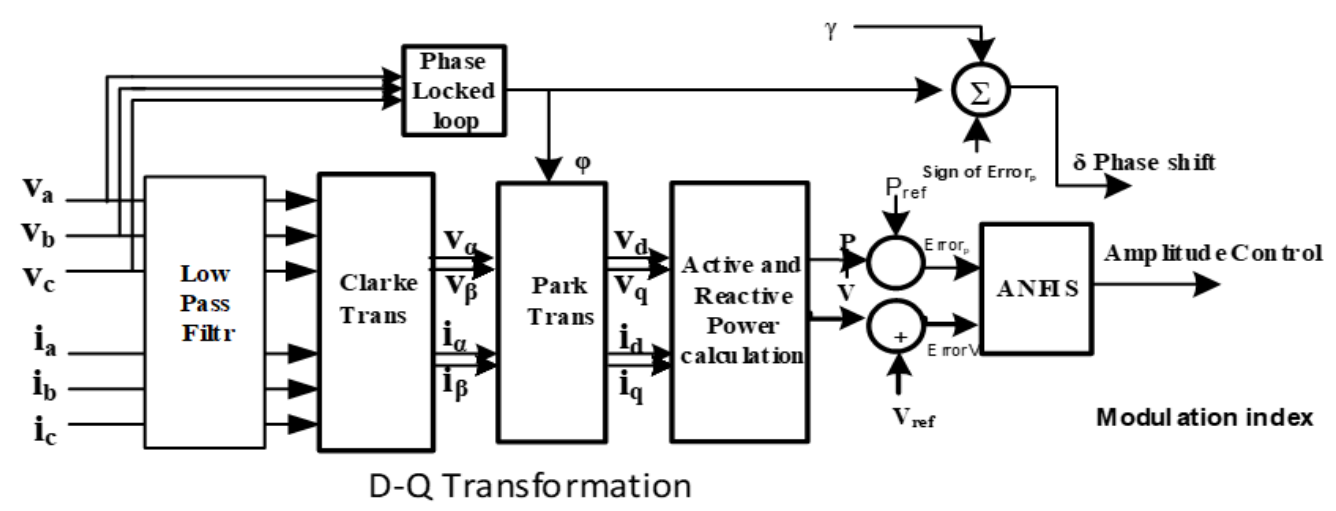

Figure 3. STATCOM control diagram

\section{CONTROLLER DESIGN}

Fuzzy logic is suitable for uncertain systems, that systems mathematical model is difficult for deriving $[15,21]$. In this study, "Takagi-Sugeno (TS)" is selected. In addition, the artificial neural network (ANN) is used for tuning the membership functions of the fuzzy controller [22-24]. The objective of the learning algorithm is to adjust the parameters of the input and output membership functions so that the Neuro-Fuzzy output matching the training data better than other types $[25,26]$. In this study, the input is 
divided into 7 "trapezoidal membership functions" that 50\% "overlapping". Thus, for 2-inputs, 49-control rule as shown in Figure 4. For tuning the Fuzzy rules by Neuro-Fuzzy, two groups of data are to be used. The input data is a vector of the Errorp, Errorv and the output $(\mathrm{m})$, which is the modulation index. Figure 5 shows the validation test.

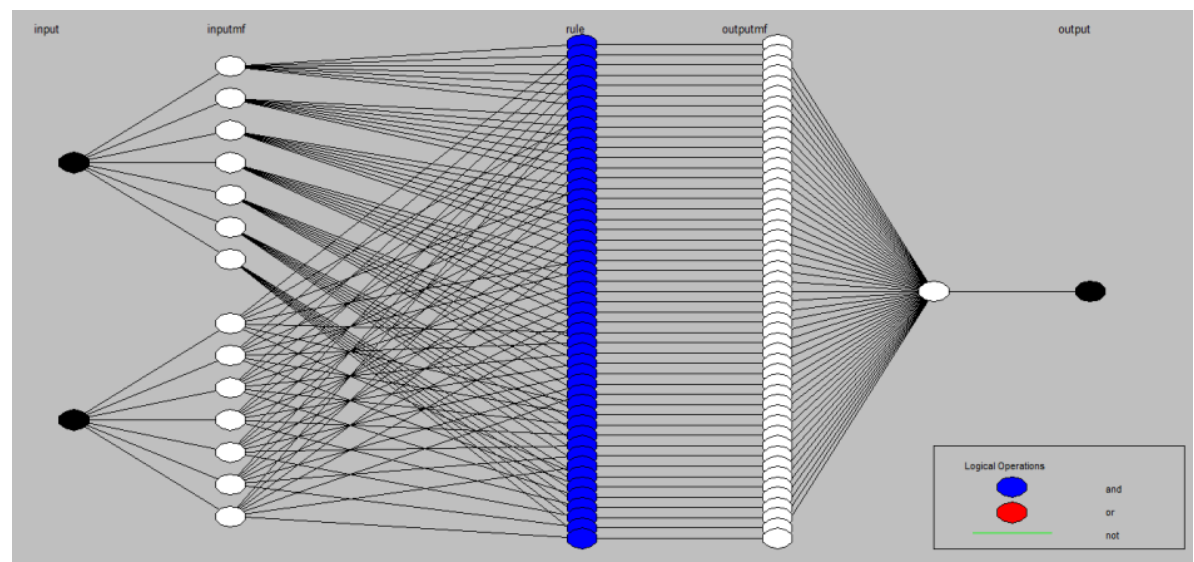

Figure 4. Fuzzy control scheme

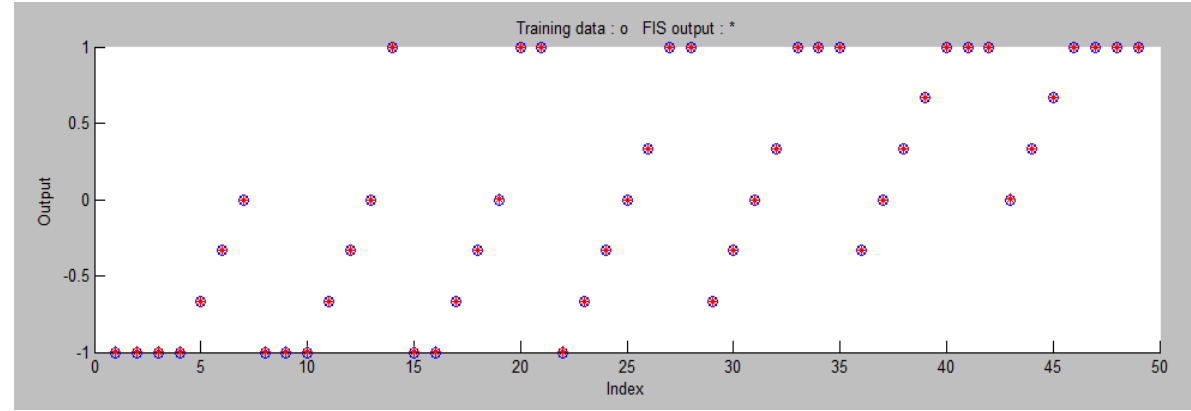

Figure 5. Fuzzy logic validation tests

The output surface of control designed is shown in Figure 6. This procedure is performed using GUI of Neuro-Fuzzy file included in the MATLAB/Toolbox. The designed controller has small in computation compared to fuzzy controller's "mamdani type". The selected system consists of single machine infinite bus bar.

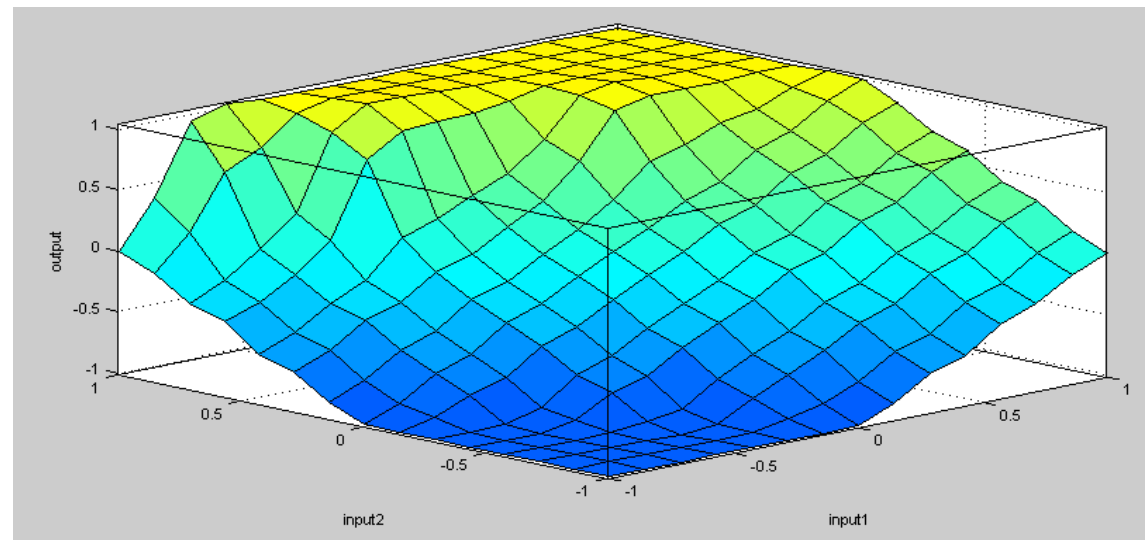

Figure 6. Control surface of STATCOM-based Neuro-fuzzy controller 


\section{SIMULATION OF SEIG WITH STATCOM}

The designed power system of SEIG with STATCOM controller has been simulated using MATLAB/Simulink. Figure 7 shows the system is simulated for investigating the STATCOM performance and the intelligent controller under changing the load. The system consists of SEIG with three phase inductive load. STATCOM is energized with a DC-link source that helps to absorb or feed the real or reactive power to or from the transmission line. The load voltage for a step-change in the load at time $=1.5 \mathrm{sec}$, the change with/without STATCOM are shown in Figure 8. The load current before and after compensator is shown in Figure 9. Figure 10 shows the frequency before/after compensation. Figure 11 shows the THD of the load voltage after the injected voltage of STATCOM. Results illustrate the capability of the STATCOM to compensate for the reactive power flow and then controlled the line current. The step changes response to the system reference signals is used for testing the performance of the controller. Figure 9 shows the compensated voltage with two-step values of injected voltage in capacitive mode (the injected voltage lag the line current). This will change in the line current above the reference values and the active power. Figure 10 shows the response to the line current step change in the capacitive mode (forward mode). The simulation results illustrated the effectiveness of the controller in optimizing the performance of STATCOM. In addition, the results prove that the proposed controller can improve the voltage profile and transient stability of the test system more efficiently than the conventional PI controller.

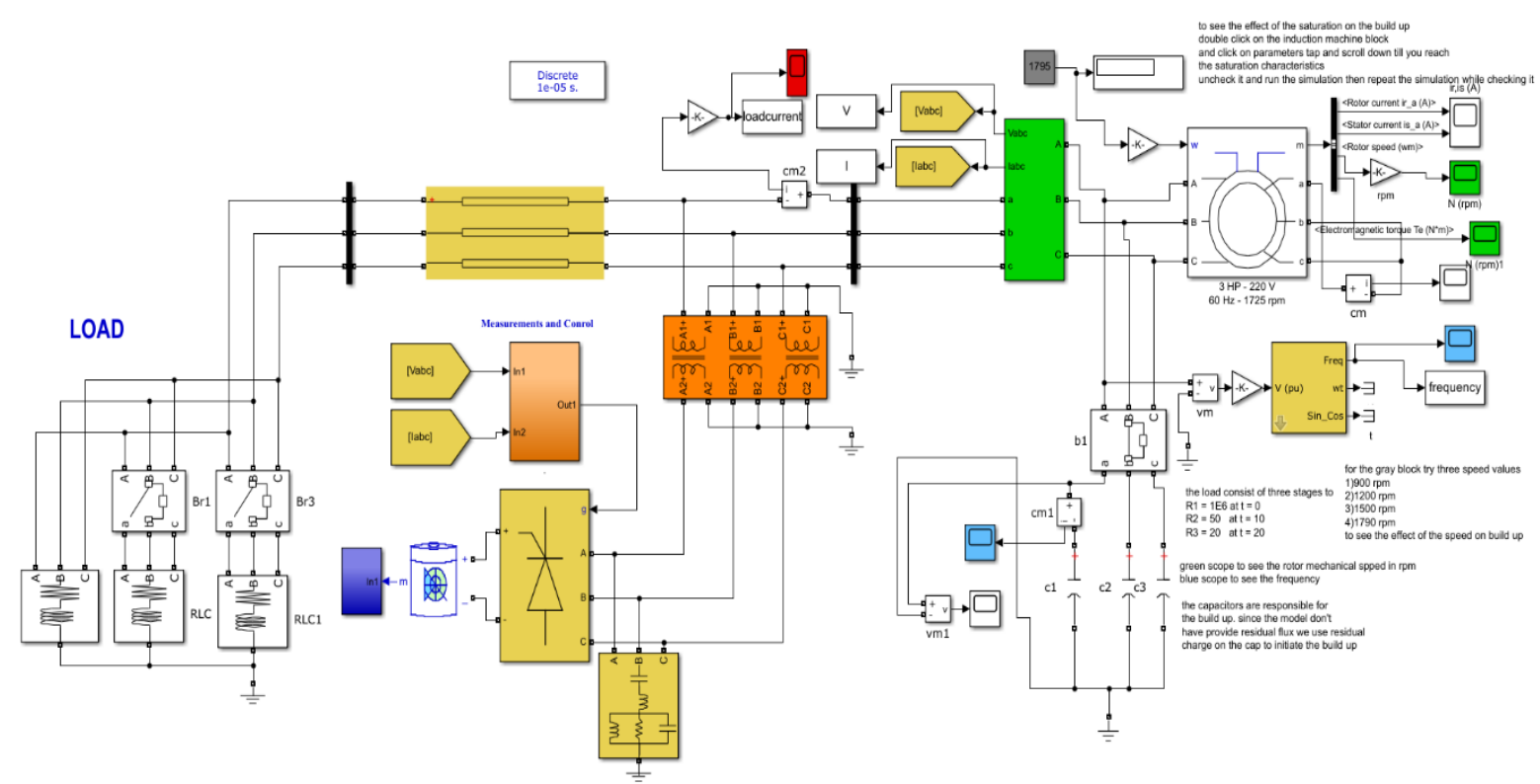

Figure 7. System model for simulation

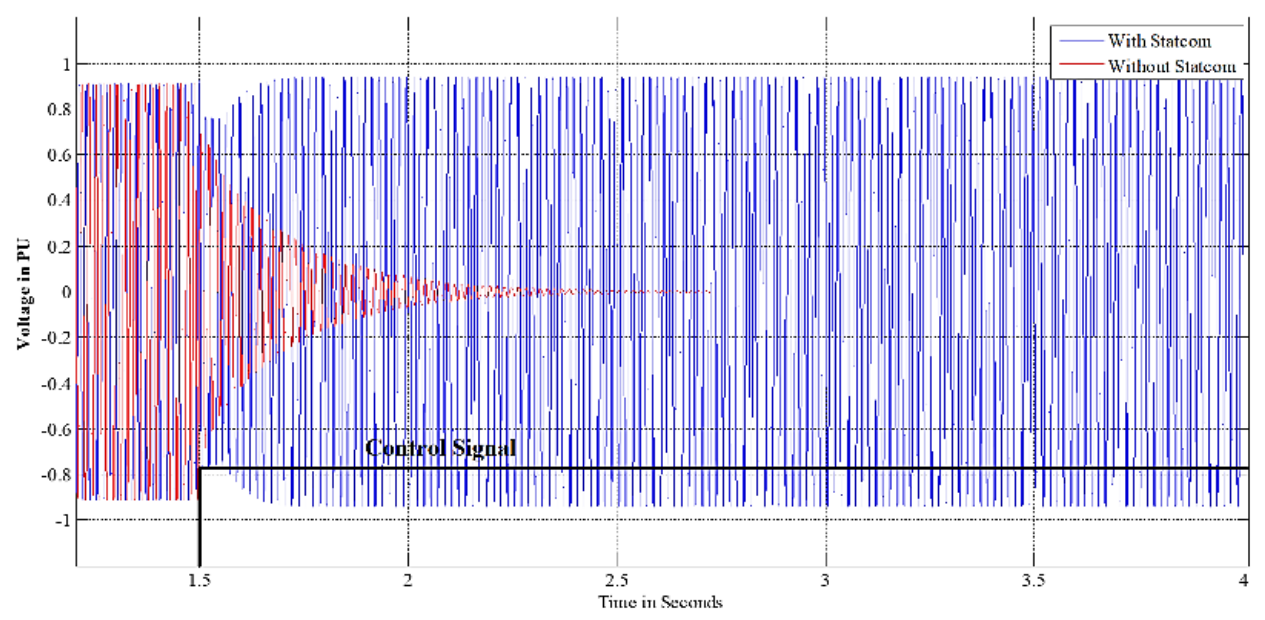

Figure 8 . The load voltage 


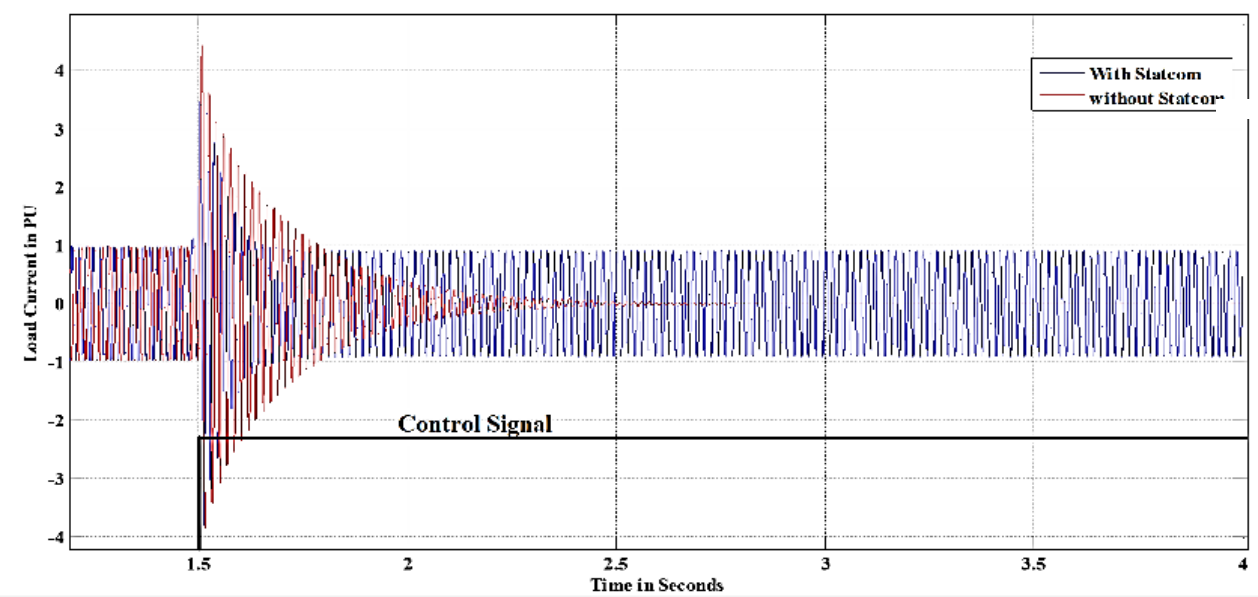

Figure 9. The line current before and after compensator

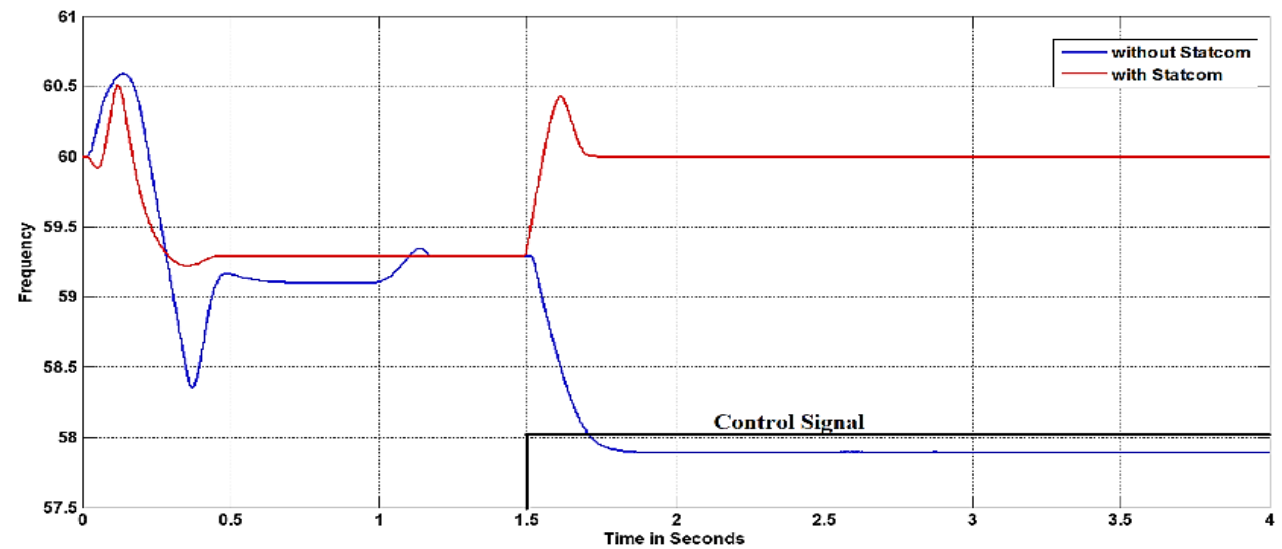

Figure 10. The line frequency before/after compensation
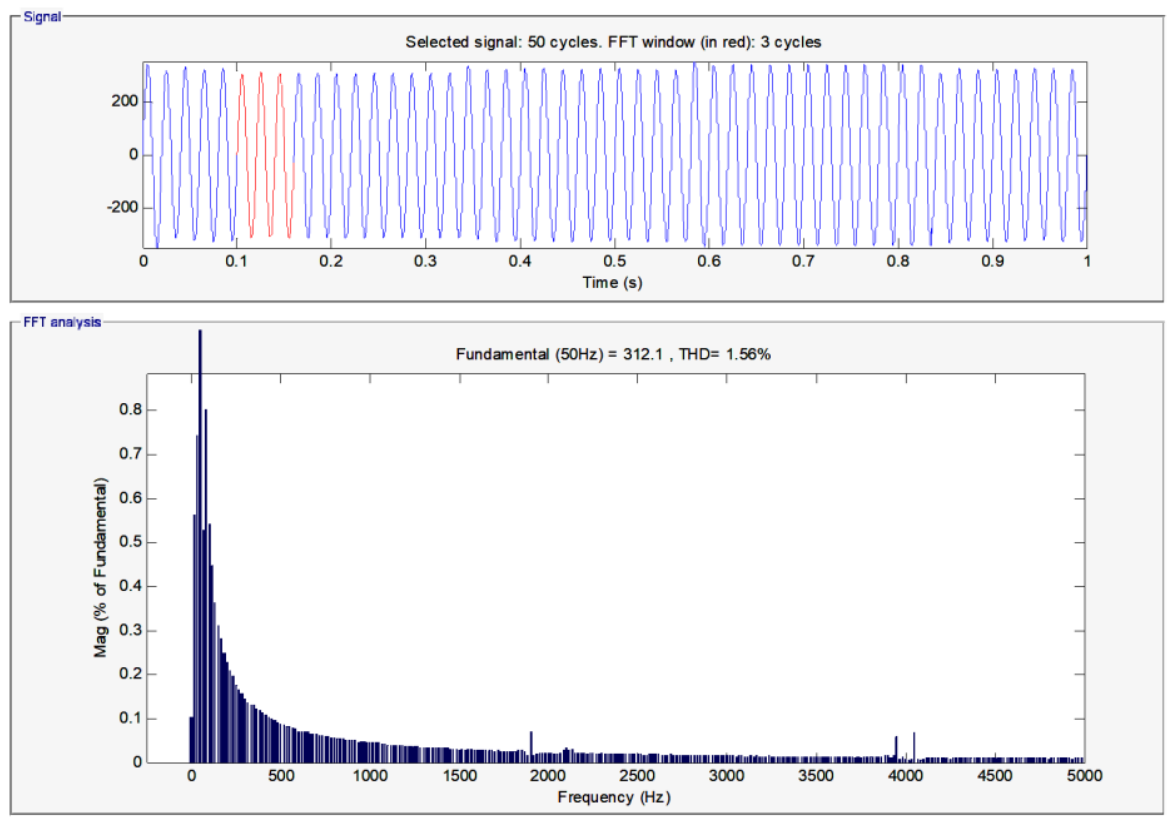

Figure 11. The THD of the load voltage after injection 


\section{CONCLUSION}

In this paper, STATCOM based on the Neuro-Fuzzy controller with SEIG is presented. The rules defined by training the error signals for real and reactive powers to initiate the tuning process. By using Takagi-Sugeno fuzzy logic system, the small response time has obtained for the controller. The controller has been tested successfully for controlling reactive power and the line current flow in the transmission. The results show that the proposed controller "Neuro-Fuzzy" can give adequate performance for the STATCOM operation. The proposed method more accurate fast in response and flexible compared with the classical PI controller.

\section{REFERENCES}

[1] S. Zhang and T. Haugland, "System design and implementation of induction generators self-excited by capacitors for maritime diesel electric propulsion systems," IEEE 13th International Conference on Power Electronics and Drive Systems (PEDS), pp. 1-6, 2019.

[2] M. G. B. Borja, S. Lescano and J. E. Luyo, "Dynamic behavior analysis of the three-phase self-excited induction generator during electricity generation with variable energy sources," IEEE CHILEAN Conference on Electrical, Electronics Engineering, Information and Communication Technologies (CHILECON), pp. 1-5, 2019.

[3] Kumar, Y. K. Chauhan and A. Shrivastava, "Design, Modeling and Performance of Static Synchronous Series Compensator Regulated Self-excited induction generator," 3rd International Conference on Recent Developments in Control, Automation \& Power Engineering (RDCAPE), pp. 519-525, 2019.

[4] Saha and S. N. Mahato, "Power Quality Improvement of a Self-Excited Induction Generator Using NFPI Controller Based Hybrid STATCOM System," IEEE International Conference on Intelligent Techniques in Control, Optimization and Signal Processing (INCOS), pp. 1-4, 2019.

[5] Ahmed, Firas Saaduldeen, Ali Nasser Hussain, and Ahmed Jadaan Ali, "Power quality improvement by using multiple sources of PV and battery for DSTATCOM based on coordinated design," In IOP Conference Series Materials Science and Engineering, vol. 745, pp. 1-18, 2020.

[6] H. Esmaeilian, E. Mohammadi, R. Fadaeinedjad, A. Bakhshai and M. Rahnama, "Design methodology to optimise induction machines based stand-alone electrical wind water pumping systems," IET Electric Power Applications, vol. 13, no. 12, pp. 2058-2069, 2019.

[7] L. Wang, et al., "Design of Three Single-phase Power-Factor-Correction Boost Converters Joined with a Controllable Singe-phase Inverter for a Self-excited Induction Generator," IEEE Industry Applications Society Annual Meeting, pp. 1-9, 2019.

[8] M. Mokhtari, et al, "Voltage Stability Improvement of an Asynchronous Wind Turbine using Static Var Compensator with Single Input Fuzzy Logic Controller," 6th International Renewable and Sustainable Energy Conference (IRSEC), pp. 1-6, 2018.

[9] B. Singh, S. S. Murthy and R. S. R. Chilipi, "STATCOM-Based Controller for a Three-Phase SEIG Feeding Single-Phase Loads," IEEE Transactions on Energy Conversion, vol. 29, no. 2, pp. 320-331, 2014.

[10] V. Ponananthi and B. R. Kumar, "Three-phase statcom controller using D-Q frame theory for a three-phase SEIG feeding single phase loads," 2nd International Conference on Electronics and Communication Systems (ICECS), pp. 926-931, 2015.

[11] M. Taoufik and S. Lassad, "Experimental stand-alone self-excited induction generator driven by a diesel motor," Journal of Electrical Systems and Information Technology, vol. 4, no. 3, pp. 377-386, 2017.

[12] M. Taoufik, B. Abdelhamid and S. Lassad, "Stand-alone self-excited induction generator driven by a wind turbine," Alexandria Engineering Journal, vol. 57, no. 2, pp 781-786, 2018

[13] N. N. Nasser and M. E. A. Farrag, "Operation of stand-alone self-excited induction generator supported by energy storage systems for small scale wind energy generation," 52nd International Universities Power Engineering Conference (UPEC), pp. 1-5, 2017.

[14] Bo Yang, G. Zeng, Y. Zhong and Z. Su, "Cascade STATCOM step wave optimization based on PSO," IEEE International Power Electronics and Application Conference and Exposition, pp. 1445-1450, 2014.

[15] G. Venkata and K. Amaresh, "Optimal Power Flow with TCSC using Genetic Algorithm," IEEE International Conference on Power Electronics, Drives and Energy Systems (PEDES), pp 1-6, 2012.

[16] R. Vanitilaand and M. Sudhakaran, "Differential Evolution algorithm based Weighted Additive FGA approach for optimal power flow using muti-type FACTS devices," Emerging Trends in Electrical Engineering and Energy Management conference (ICETEEEM), pp. 198-204, 2012.

[17] Liu Qing and Wang Zengzing, "Coordinated design of multiple FACTS controllers based on fuzzy immune coevolutionary Algorithm," IEEE Power and Energy Society General Meeting, pp. 1-6, 2009.

[18] S. Panda, and N. P. Padhy, "Comparison of particle swarm optimization and genetic algorithm for FACTS-based controller design," Appl. Soft Compute., vol. 8, no. 4, pp. 1418-1427, 2008.

[19] Anulal A. M., Archana Mohan and Lathika B. S., "Reactive power compensation of wind-diesel hybrid ystem using STATCOM with Fuzzy tuned and ANFIS tuned PID controllers," IEEE Conference International Conference on Control Communication \& Computing India (ICCC), pp. 325-330, 2015.

[20] G.Farivar, B. Hredzak and Vassilios G. Agelidis, "Decoupled Control System for Cascaded H-Bridge Multilevel Converter Based STATCOM," IEEE Transactions on Industrial Electronics, vol. 63, no. 1, pp. 322-331, 2016.

[21] Ali, A. J., Farej, Z., and Sultan, N., "Performance evaluation of a hybrid fuzzy logic controller based on genetic algorithm for three phase induction motor drive," International Journal of Power Electronics and Drive Systems (IJPEDS), vol. 10, no. 1, pp. 117-127, 2019. 
[22] V. Ponananthi and B. Rajesh Kumar, "Three-phase statcom controller using D-Q frame theory for a three-phase SEIG feeding single phase loads," IEEE Conference, 2nd International Conference Electronics and Communication Systems (ICECS), pp. 926-931, 2015.

[23] Mohammed Y. Suliman and Sameer Sadoon Al-Juboori, "Design of Fast Real Time Controller for the Dynamic Voltage Restorer Based on Instantaneous Power Theory," International Journal of Energy and Power Engineering, vol. 5, no. 2-1, pp. 1-6, 2016.

[24] Zozan Saadallah Hussain; Ali, Ahmed J; Allu, Ahmed A; Rakan Khalil Antar, "Improvement of protection relay with a single phase autore-closing mechanism based on artificial neural network," International Journal of Power Electronics and Drive Systems (IJPEDS), vol. 11, no. 1, pp. 505-514, 2020.

[25] Mohammed Y. Suliman, M. E. Farrag and S. M. Bashi, "Design of Fast Real Time Controller for the SSSC Based on Tanagi-Sugeno (TS) Ataptive Neuro-Fuzzy Control System," International Conference on Renewable Energy and Power Quality, pp. 1025-1030, 2014.

[26] S. Sumathi and Bansilal, "Artificial neural network application for voltage control and power flow control in power systems with UPFC," IEEE International Conference on Emerging Research in Electronics, Computer Science and Technology (ICERECT), pp 403-407, 2015.

\section{BIOGRAPHIES OF AUTHORS}
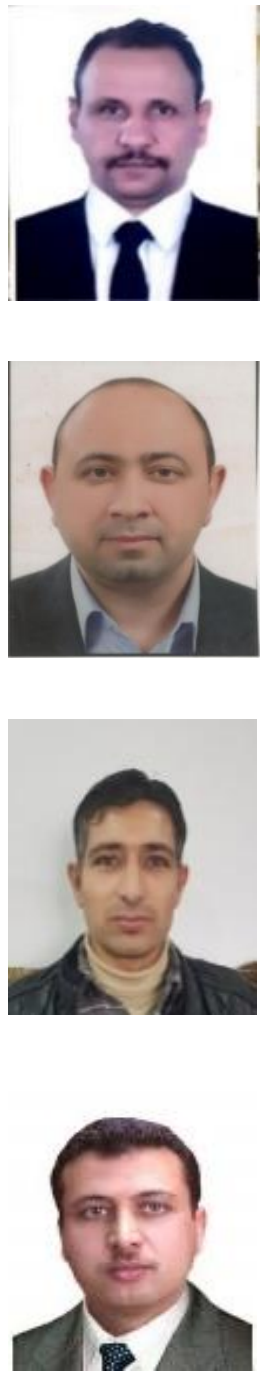

Ahmed J. is a lecturer at Dep. of power engineering technology/ Engineering Technical College/Mosul. He has completed BSc and MSc from Al-Thechnologia Unversity, Baghdad in 1995 and 2004 respectively in Electrical Engineering. He has finished his Ph.D. in Electrical Machines from university of Mosul in 2012. He has been Bunsvuer Univesity, Germany in Research Scholarship for 6 months during his Ph.D. studying period. His filed of work concentrate on Adaptive and Intelgent control Systems, Electric machines Designe and Drives. Now he is Head Dep. of Power Engineering Technology at Engineering Technical College, Mosul, Iraq.

Mohammed Y. Suliman received his B.Sc, M.Sc. and Ph. D. degrees from University of Mosul, Iraq in 1995, 1998 and 2014, respectively. Currently, he is an Assistance Professor, in the Technical College, Northern Technical University. His research interests, include power system assessment, Power Electronics, FACTS, Renewable energy.

Nashwan S. Sultan. B.Sc in Power Technical Engineering, Northern Technical University in 2008 with grade very Good with woner degree. MSc in Electrical Engineering, Control Engineering from Electrical Eng. Dept., College of Engineering, University of Mosul in 2013 with grade very Good. Currently he is an Assisting Lecturer at the Department Power Technical Engineering, Engineering Technical College, Mosul, Iraq.

Laith A. Khalaf is a lecture at department of Power Engineering Techniques, Engineering Technical College, Mosul, Northern Technical University. He has completed B.Sc.and M.Sc. degree from Al-Thechnologia University, Baghdad In 1995 and 2001 respectively in Electrical engineering department Power \& Machines. His filed of work concentrate on Adaptive and Intelligent pwer electronics Electric machines Design and Drives. Now he is a Lecturer at Power Engineering Techniques department, Technical Engineering College, Mosul, Iraq. 